\title{
Radiological assessment of the atlantoaxial distance in Down's syndrome
}

\author{
M J G Cremers, L Ramos, E Bol, J van Gijn
}

\begin{abstract}
People with Down's syndrome are predisposed to atlantoaxial instability. As part of a study to determine whether those with Down's syndrome should be screened for atlantoaxial instability before they participate in sport, a series of 279 children, aged 6 to 17 years was investigated radiologically. Lateral radiographs of the cervical spine were taken in neutral position and in flexion. The magnification factor was assessed by means of a marker attached to the nape of the neck. After correction for magnification $15 \%$ of the patients were found to have an atlantoaxial distance greater than $4 \mathrm{~mm}$ on the flexion film, especially boys under 11 years of age. However, sex and age together explained at most $9 \%$ of the variation in atlantoaxial distance. The maximum distance found was $6.5 \mathrm{~mm}$. The disagreement between the means of first and second measurements by the same (test-retest) and by another (inter-) observer was more for those taken in the neutral position than in flexion. On a group level the results for reliability were satisfactory.
\end{abstract}

(Arch Dis Child 1993; 69: 347-350)

Atlantoaxial instability in Down's syndrome is a well known condition. ${ }^{1-3}$ Before those with Down's syndrome are allowed to participate in sports some physicians think it necessary to identify those at risk of accidental damage to the spinal cord. It is of great importance to the quality of life of children with Down's syndrome to assess the real need of restricting participation in sports for those who have an atlantoaxial distance exceeding 4 or $5 \mathrm{~mm} .{ }^{45}$ To meet this need we initiated a research project into atlantoaxial instability in Down's syndrome. With this screening aspect in mind, it is relevant to study the reliability of radiological methods for measuring the distance between atlas and axis. So far the simplest way of measuring the atlantoaxial distance is by $x$ ray imaging of the cervical spine on a lateral film, both in neutral position and in flexion, and by correcting the distance obtained for magnification. Hinck and Hopkins, ${ }^{6}$ and Locke $e t a l^{7}$ have established normal values for the atlantoaxial distance in adults and children. Locke et al measured this distance in 200 normal children and studied the influence of sex, age, film to tube distance, position, and reader error. They found that in radiographs of the subject supine, made with a 40 inch tube to film distance, no child had an atlas to dens distance greater than $4 \mathrm{~mm}$. Changes in position, film to tube distance, and variance in reader measurements interacted in such a way that it was difficult to draw specific conclusions about these factors. Tube to film distance did not affect the atlanto to dens distance in the neutral and flexion positions. In the extension position, however, there was a significant difference. ${ }^{7}$ As Locke et al based their conclusions on the results of a one centre study, the influence of the magnification was probably consistent. As far as we know only Selby et al paid special attention to the reliability and to the reproducibility of the atlantoaxial distance measurement in a group of children with Down's syndrome, by repeating the study within 10 minutes in 19 children. ${ }^{8}$ The results were different, and the authors assumed that changes in muscle tone might have contributed to the lack of stability. In this part of our research project we studied the following in a population of children with Down's syndrome: (1) the reliability of the atlantoaxial distance measured on radiographs, (2) the influence of the magnification on the distance measured on the radiographs, and (3) the influence of gender and age on the atlantoaxial distance.

\section{Subjects and methods}

The population for this study consisted of 400 children with Down's syndrome, aged 6-17 years, from special schools all over the Netherlands. Exact figures about the total number of children with Down's syndrome in these schools are not available, but a realistic estimation is between 1000 and 1500 in this age group. The parents were informed about the purpose of the research project and about the benefits and the risks; all subjects gave their written consent by proxy. The parents themselves arranged that the radiographs of the cervical spine of their child were taken in a nearby hospital. About 40 different hospitals were involved. All parents received a letter with instructions for the radiologist. This letter explained the reason for $x$ ray imaging and the background of the entire project about Down's syndrome and sports. Lateral radiographs of the cervical spine were taken in two positions: in neutral position and in active flexion. In order to assess the magnification factor, we gave the instruction that a marker (a large paperclip) should be fixed with adhesive tape to the nape of the neck, overlying the spinal processes of the cervical vertebrae. The paperclip was then attached to the radiograph and measured. The magnification factor was 


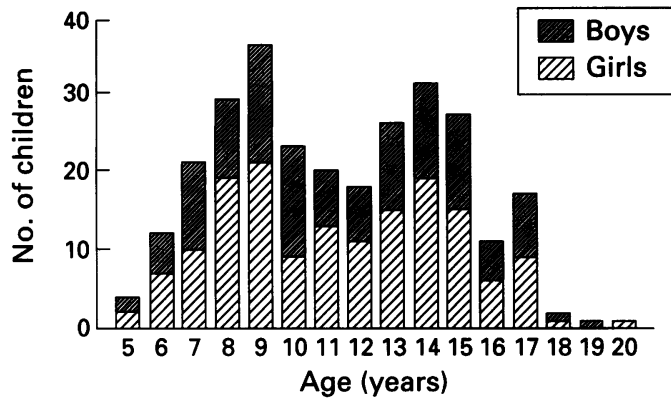

Age and sex distribution of 279 children studied (158 boys, 121 girls).

calculated from the ratio between the lengths of the real marker and its image projected on the radiograph. All radiographs were assessed by a single radiologist.

This study is based on the radiographs of 279 children that we could collect at a set time. The age and sex distribution of the children are shown in the figure. The two peaks in the age distribution, with a division at about 11 years, correspond with the number of births to women over 35 years in the Netherlands in the years these children were born.

The atlantoaxial distance is the distance between the posterior rim of the anterior arch of the atlas and the adjacent axis. When these lines did not run parallel, the smallest and largest distances between these lines were averaged. After nine months 25 radiographs were chosen at random and reassessed by the same radiologist, without access to the previous results. These radiographs were also assessed by a second radiologist.

On the basis of the study of Locke $e t a l^{7}$ we decided to consider an atlantoaxial distance greater than $4 \mathrm{~mm}$ as abnormal. All children with an abnormal atlantoaxial distance on the first radiograph took part in a further study on participation in sports. All children were examined neurologically by the first author at least once. This included assessment of muscle power of the biceps and triceps, flexion and extension of the wrist, flexion and extension of the fingers, flexion of the hip, and flexion and extension of the knee and foot. Jaw, knee, and ankle jerks and the plantar reflexes were also examined, as was muscle tone and passive movement of the elbow, wrist, knee, and ankle. Only (sub)clonus of the knee or ankle jerk or Babinski's sign were considered as pathological.

\section{Results}

The results of $x$ ray imaging are listed in table 1 , separately for sex and age. The division in age classes was chosen in accordance with the bimodal distribution in the study group. The atlantoaxial distance, uncorrected for magnification, varied between 0.6 and $6.5 \mathrm{~mm}$. The magnification factor ranged from 1.02 to 1.73 (mode $1 \cdot 17$, mean $1 \cdot 20$ ). When an atlantoaxial distance of $4 \mathrm{~mm}$ was taken as threshold value, uncorrected, as in all other studies, 88 of the 279 children (32\%) had atlantoaxial instability. To eliminate the possible difference in film-focus distance in the $\mathbf{4 0}$ hospitals that were involved in this study, we used the real atlantoaxial distance, that is the distance after correction for magnification. We then found 41 of the 279 distances greater than $4 \mathrm{~mm}$ (15\%, table 2).

The test-retest and interobserver reliability of atlantoaxial measurements made by two radiologists is shown in tables 3 and 4 . On average, observer 1 reported longer distances for the first measurements than for the second, and on both occasions the measured distances were greater than those reported by observer 2 . There was no significant difference between measurements of radiographs in test-retest or in interobserver comparison neither in neutral position nor in flexion. Cohen's $\kappa$, a measure for agreement between two observers, which takes account of agreement by chance (maximum value 1.0 ), was 0.49 when the measurements were divided into three categories. This indicates moderate agreement. ${ }^{9}$

The variance in measured atlantoaxial distances may be partially explained by sex and age (table 5). Analysis of variance with sex and age as independent factors, in a two by two factorial design, resulted in a coefficient of

Table 1 Atlantoaxial distance: mean (SD) and 95\% confidence interval $(C I)^{\star}$ in $\mathrm{mm}$, corrected for magnification $(n=279)$

\begin{tabular}{llll}
\hline & Mean $(S D)$ & No & $95 \%$ CI \\
\hline All subjects & & & \\
$\quad$ Neutral & $2.37(0.80)$ & 279 & 2.28 to 2.47 \\
$\quad$ Flexion & $3.10(0.85)$ & 279 & 3.00 to 3.20 \\
Boys $\leqslant 11$ years & & & \\
$\quad$ Neutral & $2.69(0.71)$ & 84 & 2.54 to 2.85 \\
$\quad \begin{array}{l}\text { Flexion } \\
\text { Boys }>11 \text { years }\end{array}$ & $3.47(0.79)$ & 84 & 3.30 to 3.64 \\
$\quad$ Neutral & $2.31(0.90)$ & 64 & 2.09 to 2.54 \\
$\quad$ Flexion & $2.99(0.92)$ & 64 & 2.76 to 3.22 \\
$\quad \begin{array}{l}\text { Girls } \leqslant 11 \text { years } \\
\quad \text { Neutral }\end{array}$ & $2.17(0.67)$ & 64 & 2.00 to 2.33 \\
$\quad$ Flexion & $2.94(0.75)$ & 64 & 2.75 to 3.13 \\
$\quad \begin{array}{l}\text { Girls }>11 \text { years } \\
\quad \text { Neutral }\end{array}$ & $2.18(0.80)$ & 52 & 1.96 to 2.41 \\
$\quad$ Flexion & $2.88(0.80)$ & 52 & 2.66 to 3.10 \\
\hline
\end{tabular}

${ }^{\star} 95 \% \mathrm{CI}$ is the range of values which contains the true population mean with a probability of 0.95 .

Table 2 Number (\%) of children with Down's syndrome and atlantoaxial instability

\begin{tabular}{|c|c|c|c|c|}
\hline & \multicolumn{2}{|c|}{ Before correction } & \multicolumn{2}{|c|}{ After correction } \\
\hline & $\leqslant 4 \mathrm{~mm}$ & $>4 \mathrm{~mm}$ & $\leqslant 4 \mathrm{~mm}$ & $>4 \mathrm{~mm}$ \\
\hline $\begin{array}{l}\text { Boys } \\
\quad \leqslant 11 \text { years } \\
>11 \text { years } \\
\text { Girls }\end{array}$ & $\begin{array}{l}42(52) \\
52(67)\end{array}$ & $\begin{array}{l}39(48) \\
25(33)\end{array}$ & $\begin{array}{l}60(74) \\
68(88)\end{array}$ & $\begin{array}{r}21(26) \\
9(12)\end{array}$ \\
\hline $\begin{array}{l}\leqslant 11 \text { years } \\
>11 \text { years }\end{array}$ & $\begin{array}{l}49(77) \\
48(84)\end{array}$ & $\begin{array}{r}15(23) \\
9(16)\end{array}$ & $\begin{array}{l}60(94) \\
50(88)\end{array}$ & $\begin{array}{l}4(6) \\
7(12)\end{array}$ \\
\hline Total & $191(68)$ & $88(32)$ & $238(85)$ & $41(15)$ \\
\hline
\end{tabular}

Table 3 Mean (SD) and 95\% confidence interval (CI) of the uncorrected atlantoaxial distance in $\mathrm{mm}$ and of the magnification factor for repeated measurements $(n=25)$

\begin{tabular}{|c|c|c|}
\hline & Mean $(S D)$ & $95 \% C I$ \\
\hline $\begin{array}{l}\text { Observer } 1 \text {, measurement } 1 \\
\text { Neutral } \\
\text { Flexion } \\
\text { Magnification }\end{array}$ & $\begin{array}{l}3 \cdot 4(1 \cdot 1) \\
4 \cdot 4(0 \cdot 9) \\
1 \cdot 2(0 \cdot 1)\end{array}$ & $\begin{array}{l}2.9 \text { to } 3.9 \\
4.0 \text { to } 4.9 \\
1.2 \text { to } 1.3\end{array}$ \\
\hline $\begin{array}{l}\text { Observer 1, measurement } 2 \\
\text { Neutral } \\
\text { Flexion }\end{array}$ & $\begin{array}{l}3 \cdot 3(1 \cdot 4) \\
4 \cdot 3(1 \cdot 1)\end{array}$ & $\begin{array}{l}2.6 \text { to } 3.9 \\
3.8 \text { to } 4.8\end{array}$ \\
\hline $\begin{array}{l}\text { Observer } 2 \\
\text { Neutral } \\
\text { Flexion } \\
\text { Magnification }\end{array}$ & $\begin{array}{l}2 \cdot 9(1 \cdot 3) \\
4 \cdot 3(1 \cdot 0) \\
1 \cdot 2(0 \cdot 1)\end{array}$ & $\begin{array}{l}2.3 \text { to } 3 \cdot 5 \\
3.8 \text { to } 4 \cdot 7 \\
1.2 \text { to } 1 \cdot 3\end{array}$ \\
\hline
\end{tabular}


Table 4 Mean, SD, and SE of the differences between test-retest and interobserver measurements of the atlantoaxial distance in $\mathrm{mm}$ made in neutral position and in flexion

\begin{tabular}{|c|c|c|c|c|c|c|}
\hline & \multicolumn{3}{|c|}{ Neutral } & \multicolumn{3}{|c|}{ Flexion } \\
\hline & Mean & $S D$ & $S E$ & Mean & $S D$ & $S E$ \\
\hline $\begin{array}{l}\text { Test-retest, observer } 1 \\
\text { Interobserver }\end{array}$ & $\begin{array}{l}0 \cdot 145 \\
0 \cdot 305\end{array}$ & $\begin{array}{l}0.692 \\
0.717\end{array}$ & $\begin{array}{l}0 \cdot 148 \\
0 \cdot 153\end{array}$ & $\begin{array}{l}0 \cdot 205 \\
0 \cdot 123\end{array}$ & $\begin{array}{l}0 \cdot 700 \\
0.630\end{array}$ & $\begin{array}{l}0 \cdot 149 \\
0 \cdot 134\end{array}$ \\
\hline
\end{tabular}

determination of $9 \cdot 4 \%$. Thus, more than $90 \%$ remains unexplained by the factors sex and age. Besides the inaccuracy of measurements, other factors may be relevant to explain the differences in the atlantoaxial distances in children, such as genetic predisposition or sporting practice.

The presence or absence of abnormal reflexes was not related to either the threshold value of $4 \mathrm{~mm}$ or the difference in the distance measured in flexion and in the neutral position. This lack of relation was also observed for the other threshold values (table 6 ).

\section{Discussion}

The prevalence of atlantoaxial instability among people with Down's syndrome depends on several factors, particularly on the threshold value and on whether or not correction is made for magnification on the radiograph. The threshold value of $4 \mathrm{~mm}$ is based on the study of Locke et $\mathrm{al}^{7}$ and is used by several investigators. ${ }^{2} 310$ In contrast, Semine et al used $4.5 \mathrm{~mm}$ as a threshold value, ${ }^{11}$ and Martel and Tishler $^{12}$ and Pueschel and Scola $5 \mathrm{~mm}^{1}$ In our opinion the normal value for the atlantoaxial distance in children with Down's syndrome should take into account the inaccuracy of the measured distance. Error might be caused by technical aspects such as the quality of the film or by observer inconsistency. Hinck and Hopkins emphasised that 'the error resulting from the use of crude measuring techniques, though unimportant in measuring distances of several centimeters, may take on statistical significance when measuring 1 or 2 $\mathrm{mm}$. This becomes particularly critical when working with values considered to be at the limits of the normal range'. ${ }^{6}$ We confirmed that, on repeated measurement, the differences between the means of two measurements of distances in neutral position were greater than those in flexion. This is probably because the absolute distance is somewhat greater in flexion than in the neutral position. Similarly, the greater length of the paperclip probably explains why there is no difference in the mean of this measured length, although the less distinct borders of bony structures may also influence the variability of the atlantoaxial
Table 6 Relation between appearance of abnormal reflexes and atlantoaxial distance

\begin{tabular}{lrrl}
\hline & $\leqslant 4 \mathrm{~mm}$ & $>4$ and $\leqslant 5 \mathrm{~mm}$ & $>5 \mathrm{~mm}$ \\
\hline No abnormal reflexes & 140 & 26 & 3 \\
With abnormal reflexes & 27 & 6 & 1 \\
Total & 167 & 32 & 4 \\
\hline
\end{tabular}

$\chi^{2} 0.33, p=0.84$.

distance. On the whole the results for the test-retest and interobserver reliability were satisfactory on group level. But the result of a single radiograph can differ substantially, according to the standard deviations in table 4 . To decrease error in the measurement of atlantoaxial distances, it would be best to use the average value of two measurements made by different observers. Pueschel et al think that the difference in the atlantoaxial distance, measured on a radiograph and on a computed tomogram, can be explained by magnification. ${ }^{13}$ As far as we know only the study of Martel and Tishler took the magnification factor into account. ${ }^{12}$ Our method is easy to perform and the magnification factor is reliable; the device proposed by Singer et al is more sophisticated. ${ }^{14}$ With correction for magnification (and an uncorrected threshold value of $4 \mathrm{~mm}$ ), we found the percentage of children with atlantoaxial instability $(15 \%)$ similar to that of other studies (performed in one centre) without correction. ${ }^{1-3}$ The question arises whether the threshold value found by Locke et $a l^{7}$ should also be corrected for magnification. After adjustment for magnification, using the mode of the magnification factors we found, the cut off value of Locke et al would be $3.4 \mathrm{~mm} ; 100$ of the 279 children had longer distances $(35 \%)$.

In our group of 279 children, the maximum atlantoaxial distance was $6.5 \mathrm{~mm}$. With a threshold value of more than $4 \mathrm{~mm}$, it does not mean that children who have a longer atlantoaxial distance are definitely at risk of spinal cord damage. No relation was found between abnormal reflexes and the atlantoaxial distance. An explanation for this could be that the appearance of abnormal reflexes is not specific for spinal lesions at the cervical level.

$x$ Ray imaging is one of the best methods to detect atlantoaxial instability, and is better than laxity assessment. ${ }^{15}$ The current normal range for values is not adequate, however, as it does not take magnification into account and the measured distances are not reliable enough in that range. Screening, in general, is only useful if prevention of accidents is possible or treatment in an early stage is

Table 5 Differences in atlantoaxial distance $(\mathrm{mm})$ in neutral position and in flexion between boys and girls and between ages

\begin{tabular}{|c|c|c|c|c|c|c|c|c|}
\hline & \multicolumn{2}{|l|}{ Boys } & \multicolumn{2}{|l|}{ Girls } & \multirow{2}{*}{\multicolumn{2}{|c|}{$\begin{array}{l}\text { Difference (SE) } \\
\text { between ages }\end{array}$}} & \multirow{2}{*}{\multicolumn{2}{|c|}{$\begin{array}{l}\text { Difference (SE) } \\
\text { between boys and girls }\end{array}$}} \\
\hline & \multirow{2}{*}{$\begin{array}{l}\leqslant 11 \text { years } \\
(n=84)\end{array}$} & \multirow{2}{*}{$\begin{array}{l}>11 \text { years } \\
(n=64)\end{array}$} & \multirow{2}{*}{$\begin{array}{l}\leqslant 11 \text { years } \\
(n=64)\end{array}$} & \multirow{2}{*}{$\begin{array}{l}>11 \text { years } \\
(n=52)\end{array}$} & & & & \\
\hline & & & & & Boys & Girls & $\leqslant 11$ years & $>11$ years \\
\hline $\begin{array}{l}\text { Neutral } \\
\text { Flexion }\end{array}$ & $\begin{array}{l}2 \cdot 69 \\
3 \cdot 47\end{array}$ & $\begin{array}{l}2 \cdot 31 \\
2 \cdot 99\end{array}$ & $\begin{array}{l}2 \cdot 17 \\
2 \cdot 94\end{array}$ & $\begin{array}{l}2 \cdot 18 \\
2 \cdot 88\end{array}$ & $\begin{array}{l}-0.38(0.14)^{\star \star} \\
-0.48(0.14)^{\star \star}\end{array}$ & $\begin{array}{r}0.01(0.16) \\
-0.06(0.16)\end{array}$ & $\begin{array}{l}0.52(0.14)^{\star \star} \\
0.53(0.14)^{\star \star}\end{array}$ & $\begin{array}{l}0 \cdot 13(0 \cdot 16) \\
0 \cdot 11(0 \cdot 16)\end{array}$ \\
\hline
\end{tabular}


available. The advice that, if atlantoaxial instability exists, certain sports should be avoided to prevent accidents has not been supported by evidence from our studies ${ }^{16}$ and those of others.

We acknowledge the help of Dr A van Driem for reassessing the radiographs.

1 Pueschel SS, Scola FH. Atlantoaxial instability in individ uals with Down syndrome: epidemiologic, radiographic and clinical studies. Pediatrics 1987; 80: 555-60.

2 Elliot S, Morton RE, Whitelaw RAJ. Atlantoaxial instability and abnormalities of the odontoid in Down's syndrome. Arch Dis Child 1988; 63: 1484-9.

3 Jagiivan B, Spencer PAS, Hosking G. Radiological screening for atlantoaxial instability in Down's syndrome. Clin Radiol 1988; 39: 661-3.

4 Committee on Sports Medicine. Atlantoaxial instability in Down's syndrome. Pediatrics $1984 ; 74: 152-3$.

5 Department of Health and Social Security. Atlanto-axial instability in people with Down's syndrome. London: DHSS 1986.

6 Hinck VC, Hopkins CE. Measurement of the atlanto-dental interval in the adult. $A \mathcal{F}$ 1960; 84: 945-51.
7 Locke GR, Gardner JI, Van Epps EF. Atlas-dens interval (ADI) in children. A survey based on 200 normal cervical spines. Am $\mathcal{F}$ Radiol 1966; 97: 135-40.

8 Selby KA, Newton RW, Gupta S, Hunt L. Clinical predictors and radiological reliability in atlantoaxial subluxation in Down's syndrome. Arch Dis Child 1991; 66: 876-8.

9 Altman DG. Practical statistics for medical research. London: Chapman and Hall, 1991: 404

10 Burke SW, French HG, Roberts JM, Johnston CE Whitecloud TS, Edmunds JO. Chronic atlanto-axial instability in Down syndrome. f Bone foint Surg [Am] 1985; 67: 1356-60.

11 Semine AA, Ertel AN, Goldberg MJ, Bull MJ. Cervical spine instability in children with Down syndrome (trisomy 21). F Bone foint Surg [Am] 1978; 60: 649-52.

12 Martel W, Tishler JM. Observations on the spine in mongoloidism. $A f R$ 1966; 97: 630-8.

13 Pueschel SM, Moon AC, Scola FH. Computerized tomography in persons with Down syndrome and atlantoaxial instability. Spine 1992; 17: 735-7.

14 Singer SJ, Rubin IL, Strauss KJ. Atlantoaxial distance in patients with Down syndrome: standardization of measurement. Radiology 1989; 164: 871-2.

15 Cremers MJG, Beijer HJM. No relation between general laxity and atlantoaxial instability in children with Down syndrome. $\mathcal{F}$ Pediatr Orthop 1993; 13: 318-21.

16 Cremers MJG. Down syndrome and sports. Utrecht: University of Utrecht, 1993. (Thesis.) 